Short Note

\title{
N-Benzoyl / (4-nitrobenzoyl)-N'-4-cyanophenyl thioureas
}

\section{Fatma Aydin}

Çanakkale Onsekiz Mart University, Department of Chemistry, 17100, Çanakkale, TURKEY

* Author to whom correspondence should be addressed; E-mail: faydin@comu.edu.tr

\begin{abstract}
:
Herein, two title compounds, N-Benzoyl-N'-4-cyanophenyl thiourea (I) and N-(4nitrobenzoyl)-N'-4-cyanophenyl thiourea (II) were synthesized in high yield, via aroyl isocyanate and 4-aminobenzonitrile. The structure of the prepared compounds was characterized by elementary analysis and FT-IR, ${ }^{1} \mathrm{H},{ }^{13} \mathrm{C}$ NMR spectroscopic methods. Cyclic voltammetric (CV) experiments were performed with glassy carbon electrode. The reduction potential values of different functional group such as nitro, cyano in title compounds were investigated using CV curves.
\end{abstract}

Keywords: N-Substituted-N'-aroyl(acyl)thioureas, CV curves, 4-aminobenzonitrile,

\section{Introduction}

N-Substituted-N'aroyl(acyl)thiourea derivatives are known to show a wide range of biological activite such as antibacterial, antifungal properties [1-3]. Moreover, some $\mathrm{N}$-aroyl(acyl)thioureas were used for extraction, separation and determination of heavy metals such as Fe, $\mathrm{Zn}$ ions [4-5]. In addition, these types of ligands are useful for analytical applications, such as potentiometric sensors for heavy metals or chemosensory for anions such as $\mathrm{F}^{-}, \mathrm{CN}^{-}$, OAc ${ }^{-}$etc. [6-7]. Furthermore, N-substituted-N'aroyl(acyl)thioureas are also useful compounds for the synthesis of biologically important heterocyclic scaffolds, such as thiohydantoins [8].

In this study, two new thiourea compounds named as N-benzoyl-N'-4-cyanophenylthiourea and N-(4nitrobenzoyl)-N'-4-cyanophenylthiourea were synthesized and their structure were characterized by elemental analysis, FT-IR and 1H-NMR and 13C-NMR spectroscopic techniques (Scheme 1). They consist of both of carbonyl and thiocarbonyl and also other functional group such as nitro and cyano. To 
know the redox potential values of these functional groups in the structure, electrochemical potential properties of title compounds as CV curves were examined.

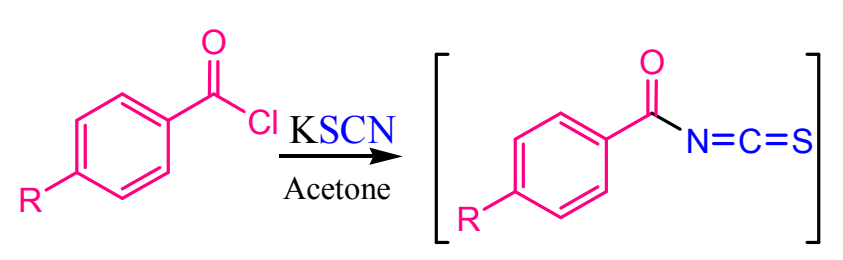

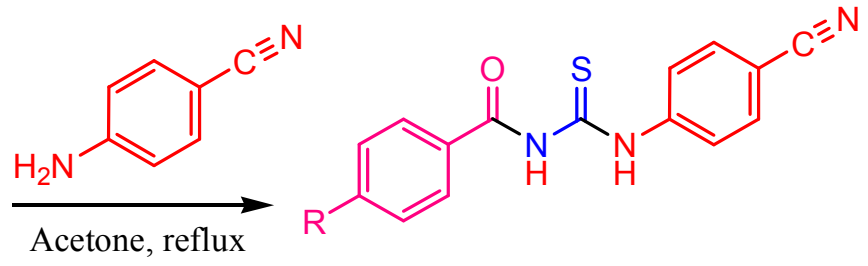

$\mathrm{R}: \mathrm{H}, \mathrm{NO}_{2}$

Scheme 1. The synthesis of N-Benzoyl / (4-nitrobenzoyl)-N'-4-cyanophenyl thioureas

A mixture of aroyl chloride (10 mmol, benzoyl- and 4-nitrobenzoyl-) and $\mathrm{KSCN}$ (0.969 g, $10 \mathrm{mmol})$ in $20 \mathrm{~mL}$ of acetone was refluxed with stirring for $1 \mathrm{~h}$, , then, a solution of $10 \mathrm{mmol}$ of 4 -cyanoaniline in $20 \mathrm{~mL}$ acetone was added drop wise to the aroyl isothiocyanate for $0.5 \mathrm{~h}$. at ambient temperature. When the solution was added completely, the resulting solution was then refluxed for $3 \mathrm{~h}$. and the progress of reaction was controlled by TLC. After cooling, the solution was poured into a beaker containing ice-water mixture. The white and yellowish precipitate was altered off and washed with distilled water several times and then dried under vacuum, respectively. Re crystallization from tetrahydrofurane yielded 87 and $84 \%$ of the pure cream and pale yellow products, respectively. Nbenzoyl-N'-(4-cyanophenyl)thiourea (I), $\mathrm{C}_{15} \mathrm{H}_{10} \mathrm{~N}_{3} \mathrm{O}_{3} \mathrm{~S}$, was obtained as cream crystals (87\%); mp. 212-213 ${ }^{\circ} \mathrm{C}$; IR (KBr pellet); $\left(\mathrm{cm}^{-1}\right): 3229\left(\mathrm{~N}-\mathrm{H}\right.$, stretch), $3030\left(\mathrm{C}=\mathrm{C}_{\text {arom }}\right), 2223(\mathrm{C} \equiv \mathrm{N}), 1662(C=O)$, 1592 (N-H, bending), 1518 (thiocarbonyl, CS-N), 1262 (N-C=S, thioureido), 1162 (carbonyl, CO-N),

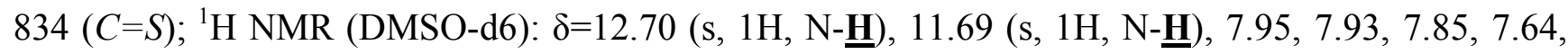
$7.49(9 \mathrm{H}, \mathrm{Ar}-\underline{\mathrm{H}}) ;{ }^{13} \mathrm{C} \mathrm{NMR}\left(\mathrm{CDCl}_{3}\right): 179.7(\underline{\mathrm{C}}=\mathrm{S}) ; 168.6(\underline{\mathrm{C}}=\mathrm{O}) ; 142.7133 .7 ; 133.5 ; 132.5 ; 129.3$, 129.1; 128.9, 124.9; 124.6; $119.1(\operatorname{Ar} \underline{C}), 108.6(\underline{C} \equiv N)$, (Supplimentary materials, Figure S1, Figure S3, S4) and Schema 2-I.

N-4-nitrobenzoyl-N'-(2-cyanophenyl)thiourea (II), $\mathrm{C}_{13} \mathrm{H}_{10} \mathrm{~N}_{4} \mathrm{O}_{3} \mathrm{~S}$, was obtained as pale yellow crystals (84\%); mp. 206-207 ${ }^{\circ} \mathrm{C}$; IR (KBr pellet); $\left(\mathrm{cm}^{-1}\right)$ : $3212(\mathrm{~N}-\mathrm{H}), 3070,3005\left(\mathrm{C}-\mathrm{H}_{\text {arom }}\right), 2225(\mathrm{C} \equiv \mathrm{N})$, $1662(\mathrm{C}=\mathrm{O}), 1592(\mathrm{~N}-\mathrm{H}$, bending), 1518 (thiocarbonyl, CS-N), 1335 (N-C=S, thioureido), 1156

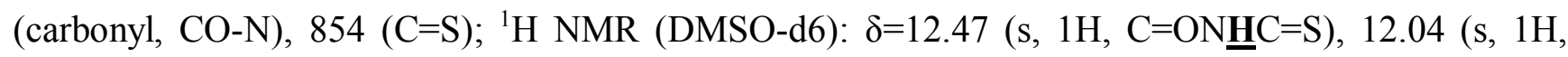
$\left.\mathrm{C}=\mathrm{SN} \underline{\mathbf{H}} \mathrm{C}=\mathrm{C}_{\mathrm{ar}}\right), 8.30,8.12,7.93,7.85$, $(8 \mathrm{H}, \mathrm{Ar}-\underline{\mathbf{H}}) ;{ }^{13} \mathrm{C} \mathrm{NMR}\left(\mathrm{CDCl}_{3}\right): 179.4(\mathrm{C}=\mathrm{S}) ; 167.0(\mathrm{C}=\mathrm{O})$; $150.3 ; 142.6 ; 138.4 ; 133.4 ; 130.8 ; 124.8 ; 123.8 ; 119.1$, (ArC $)$; 108.7 (ㅁN), (Supplimentary materials, Figure S2, Figure S5, Figure S6) and Scheme 2-II. 


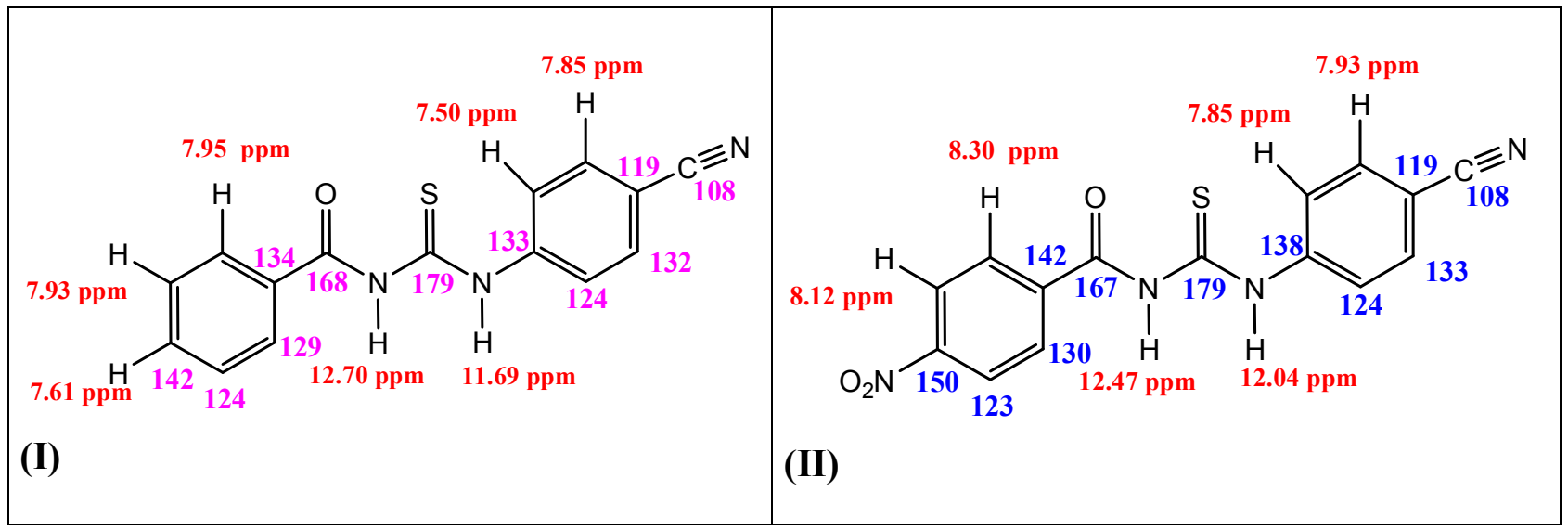

Scheme 2. ${ }^{1} \mathrm{H}$ and ${ }^{13} \mathrm{C}$ NMR chemical shift of the title compounds in DMSO-d6

\section{Electrochemical studies:}

The electrochemical properties of aroylthiourea derivatives were investigated further by using cyclic voltammetry analysis in order to determine the redox potentials. The cyclic voltammetry $(\mathrm{CV})$ curves of the compounds are given in Fig. 2. The curves of $4 \times 10^{-3} \mathrm{M}$ N-Benzoyl-N'-4-cyanophenyl thiourea and $\mathrm{N}$-(4-nitrobenzoyl)-N'-4-cyanophenyl thiourea were recorded in acetonitrile ( $\mathrm{AcN}$ ) solution containing $0.1 \mathrm{M}$ lithium perchlorate $\left(\mathrm{LiClO}_{4}\right)$ as a supporting electrolyte at a scan rate of $0.01 \mathrm{~V} \cdot \mathrm{s}^{-1}$ in the potential range of $0.0 \mathrm{~V}$ and $-2.0 \mathrm{~V}$ on glassy carbon electrode $(\mathrm{GCE}) . \mathrm{Ag} / \mathrm{AgCl} / \mathrm{Cl}^{-}$electrode and platinum wire was used as reference and counter electrodes, respectively in the three electrode cell. The electrochemical measurements were carried out by using electrochemical analyzer (Gamry, Interface 1000). 


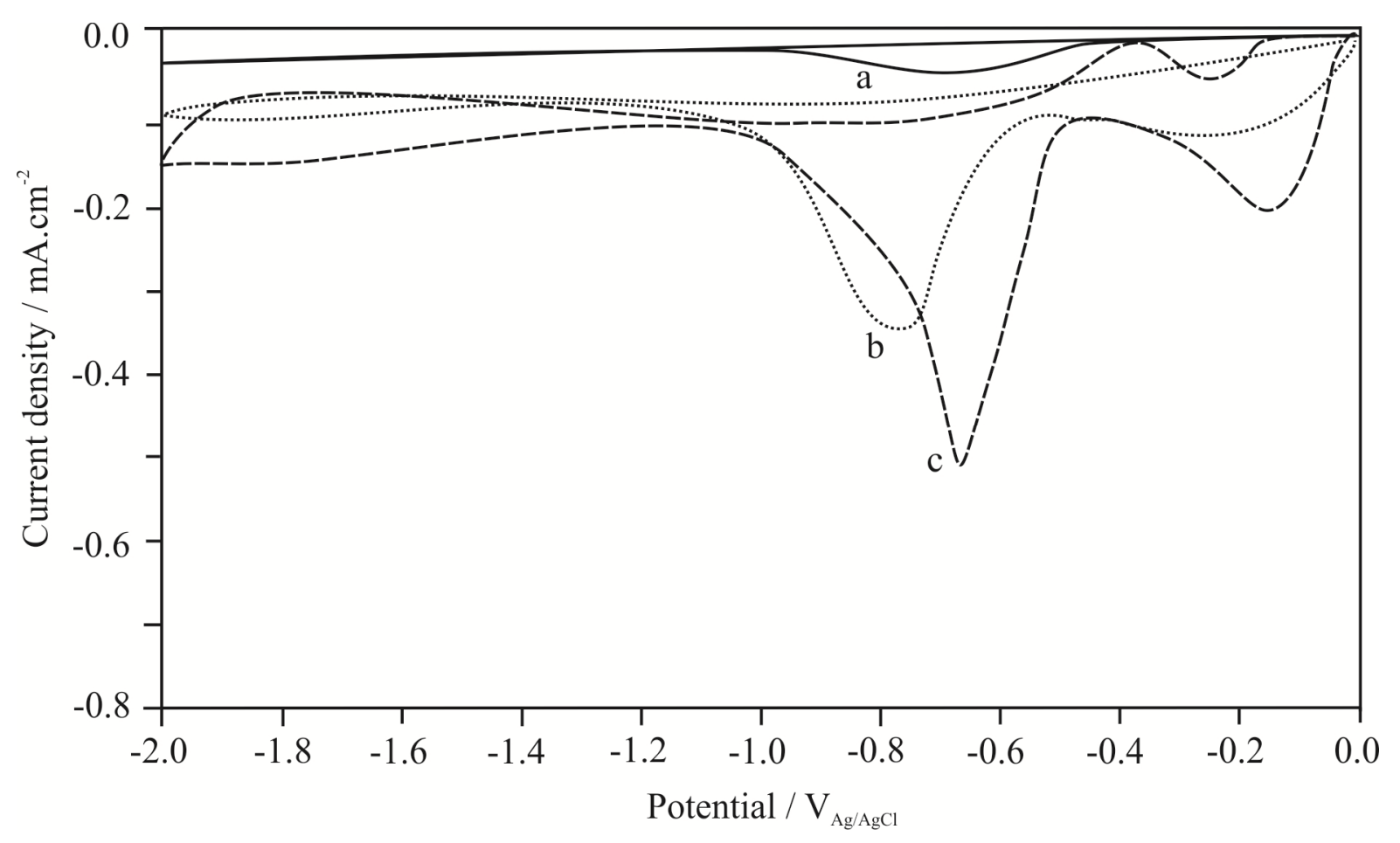

Figure 2. Cyclic voltammograms of acetonitrile solution containing $0.1 \mathrm{M} \mathrm{LiClO}_{4}$ (a), with $4 \times 10^{-3} \mathrm{M} \mathrm{N}$ Benzoyl-N'-4-cyanophenyl thiourea (b), with $4 \times 10^{-3} \mathrm{M}$ N-(4-nitrobenzoyl)-N'-4-cyanophenyl thiourea (c).

One and two cathodic peaks were observed for N-Benzoyl-N'-4-cyanophenyl thiourea (I) and N-(4nitrobenzoyl)-N'-4-cyanophenyl thiourea (II), respectively. As could be seen from Fig. 2, the first peak observed about $-0.130 \mathrm{mV}$ for compound II, can be attributed to the reduction of the $-\mathrm{NO}_{2}$ (nitro) group [9]. The second peaks observed about $-0.770 \mathrm{mV}$ (b) and $-0.650 \mathrm{mV}$ (c) for compound I and II were thought to be due to the reduction of $\mathrm{C} \equiv \mathrm{N}$ groups of the molecules, respectively. It is clearly seen that, more sharpened peaks were observed in the presence of $-\mathrm{NO}_{2}$ group and the reduction potentials shifted to more positive values. Additionally, it was observed that the $\mathrm{C}=\mathrm{O}$ and $\mathrm{C}=\mathrm{S}$ functional groups were not reduced due to the tautomeric equilibrium in acetonitrile solution (Scheme 3) [10].

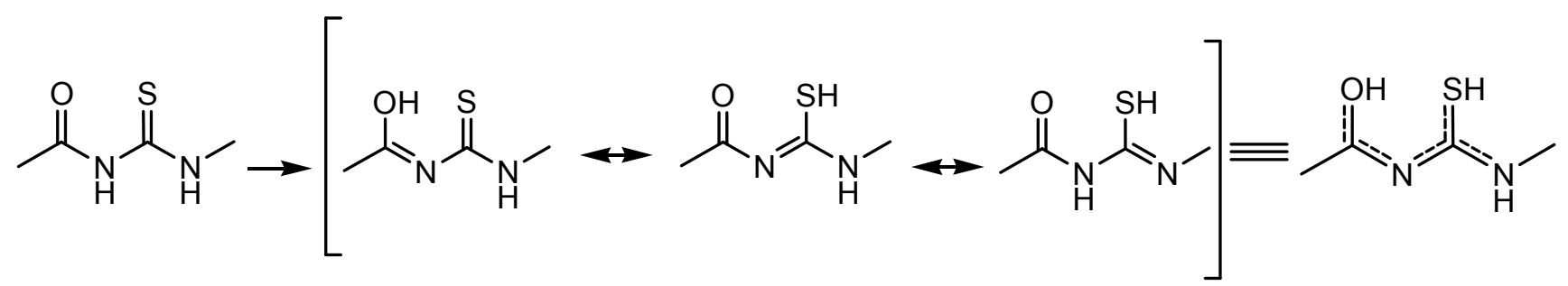

Scheme 3. The tautomeric equlibrium of amide-imidic acide and thiocarbonyl-thioureido. 


\section{Conclusion}

Two new thioureas, N-benzoyl-N'-(2-cyanophenyl)thiourea and N-(4-nitrobenzoyl)-N'-(2cyanophenyl)thiourea, were prepared in high via aroylisothiocyanate salts. Their cyclic voltammetric data were investigated. It has been determined that reduced potential of the functional groups have change due to conjugation. It was observed that the inductive effect of the nitro group affected the reduction potential of cyano group.

\section{Supplenentary Materials}

FT-IR, 1H-NMR and 13C-NMR spectra are reported in the supplementary materials as Figures S1-S6.

\section{Acknowledgements}

The financial support of Çanakkale Onsekiz Mart University Grants Commission for a research grant (Project Number: 2016 /672) is gratefully acknowledged.

\section{References and Notes}

1. Mahdavi, M.; Shirazi, M.S.; Taherhani, R.; Saeedi, M.; Alipour, E.; Moghadam, F.H.; Moradi, A.; Nadri, H.; Emami, S.; Firoozpour, L.; Shafiee, A.; Forouma, A. Synthesis, biological evaluation and docking study of 3-aroyl-1-(4-sulfamoyphenyl)thiourea derivatives as 15liopxygenase inhibitors Eur J Med Chem. 2014, 82,308-313.

2. Saeed, S.; Rashid, N.; Jones, P.G.; Ali, M.; Hussain, R. Synthesis, characterization and biological evaluation of some thiourea derivatives bearing moiety as potential antimicrobial and anticancer agents Eur J Med Chem. 2010, 45, 1323-1331.

3. Saeed, A.; Flörke, U.; Erben, M.F.; A review on the chemistry, coordination, structure and biological properties of 1-(acyl/aroyl)-3-(substituted) thioureas. J Sulfur Chem. 2014, 35, 318355.

4. Koch, K.R. New chemistry with old ligands: N-alkyl- and N,N-dialkyl-N'-acyl(aroyl)thioureas in coordination, analytical and process chemistry of the platinum group metals. Coordination Chemistry Reviews 2001, 216-217: 473-488.

5. Alkherraz, A.M.; Lusta, Z.I.; Zubi, A.E. Synthesis and use of thiourea derivative (1-phenyl-3benzoyl-2-thiourea) for extraction of cadmium ion. Int J Chem Mol Nucl Mater Metall Eng. 2014, 8, 108-110.

6. Aydın, F.; Tunoğlu, N.; Aykac, D.; Arslan, N.B.; Kazak, C., Synthesis and structural X-ray analysis of 1,1'-(naphthalene-1,8-diyl)-3,3'-dibenzoyl-bisthiourea and its use as anion-binding receptor, Turk J Chem, 2012, 36, 764-777. 
7. Aydın, F.; Dagcı, E.; N,N'-Bis-(4-nitrophenylcarbamothioyl)phthalamide, molbank, 2013, M809.

8. Ersen, D.; Ulger, M.; Mangelinckx, S.; Gemili, M.; Şahin, E.; Nural, Y., Syntehesis and anti(myco)bacterial activity of novel 5,5-diphenylpyrrolidine $\mathrm{N}$-aroylthiourea derivatives and a functionalized hexahydro-1H-pyrrolo[1,2-c]imidazole, Med. Chem. Res., 2017, 26, 2152-2160.

9. Olson, E.J.; Isley, W.C.; Brennan, J.E.; Cramer, C.J. and Buhlmann, P., Electrochemical reduction of 2,4-dinitrotoluene in aprotic and $\mathrm{pH}$ buffered media, J. Phys. Chem. C 2015, 119, 13088-13097.

10. Saeed, A.; Flörke, U. and Erben, M.F., A revive on the chemistry, coordination, structure and biological properties of 1-(acyl/aroyl)-3-(substituted) thioureas, J Sulfur Chem. 2014, 35, 3, 318-355. 